\title{
Internalism and the Problem of Stored Beliefs
}

\author{
Matthew Frise ${ }^{1}$
}

Received: 3 September 2015/Accepted: 21 May 2016/Published online: 31 May 2016

(C) Springer Science+Business Media Dordrecht 2016

\begin{abstract}
A belief is stored if it is in no way before the subject's mind. The problem of stored beliefs is that of satisfactorily explaining how the stored beliefs which seem justified are indeed justified. In this paper I challenge the two main internalist attempts to solve this problem. Internalism about epistemic justification, at a minimum, states that one's mental life alone determines what one is justified in believing. First I dispute the attempt from epistemic conservatism, which states that believing justifies retaining belief. Then I defend the attempt from dispositionalism, which assigns a justifying role to dispositions, from some key objections. But by drawing on cognitive psychological research I show that, for internalism, the problem of stored beliefs remains.
\end{abstract}

\section{Introduction}

Most justified beliefs, it seems, are stored in memory. Usually, our justified beliefs about our past, geography, philosophy, world history, and most other topics are nonoccurrent. We are not thinking about, reasoning from, acting from, or having an experience concerning these beliefs or their content. Of course, a belief can be both stored and occurrent, just as a song can be both stored and playing on one's computer. But most justified beliefs are merely stored (hereafter stored). They are in no way before our minds.

The problem of stored beliefs is the problem of satisfactorily explaining how the stored beliefs which seem justified are indeed justified. In this paper, I argue that internalists about epistemic justification have not solved this problem for their view. Internalism, at a minimum, states two theses. First, that possible beings who are

Matthew Frise

matthew_frise@baylor.edu

1 Baylor University, One Bear Place \#97273, Waco, TX 76798-7273, USA 
mentally identical are, to the same degree, justified in believing the same propositions. ${ }^{1}$ No contingent fact about a subject's environment affects her justification unless it affects her mental states. Someone whose experiences are identical to yours but who is massively deceived by an evil demon is justified in believing the same propositions you are. Second, that all justifying features are mental. It is controversial among internalists exactly what these features are, and controversial whether these features must be specially accessible or made aware to the subject. This paper remains neutral on these controversies. Internalism here covers all views that entail the two minimal theses. Most views in this broad range add further necessary conditions on having justification, restricting which mental features justify.

Some philosophers deny internalism because they think it cannot solve the problem of stored beliefs. ${ }^{2}$ They think that even if internalism accounts for the justification of some justified stored beliefs, our mental lives are too impoverished to account for the justification of all. If internalism cannot solve the problem, it is significantly discredited. This result is especially noteworthy when internalism picks out (as it does here) a broad range of views. If the problem has no solution when we assume just the two minimal theses, then every variety of internalism is threatened. Varieties that add further necessary conditions on justification arguably worsen the problem. The varieties might restrict justifying mental features to those which are factive, those which the subject is aware of, those specially accessible to the subject, those which consist in seemings, etc. If the mental life is too meager to account for some array of justification, the restricted mental life is too meager too.

What's more, without a solution to the problem, one of the best arguments for internalism fails. The argument alleges that internalism's implications match our intuitions about when a subject is or is not justified in believing a proposition. ${ }^{3}$ Internalism "gets the cases right". If internalism cannot solve the problem of stored beliefs, it gets some cases wrong.

While I think internalists can solve this problem, my aim in this paper is to challenge the only internalist attempts in the literature. ${ }^{4}$ First I dispute the unchallenged attempt from epistemic conservatism. Then I examine the attempt from a view I call dispositionalism, which assigns a justifying role to dispositions. I clarify and develop dispositionalism, and defend its attempt from some key objections. But, by drawing on cognitive psychological research, I show that the problem of stored beliefs remains. If I am correct, internalism's only hope lies in a fresh defense. And the prospects for such a defense remain unclear.

\footnotetext{
${ }^{1}$ Cf. Conee and Feldman (2004: 56).

2 See Goldman (1999, 2009, 2011), Senor (1993, 2009), and Williamson (2007). Cf. Frise (2015), Harman (1986) and Huemer (1999). Pappas (1980) discovered the problem, Senor (1993) directed it at internalism, and Goldman (1999) named it.

3 Cf. Conee and Feldman (2004: 58-61).

${ }^{4}$ I defend an internalist solution in Frise (manuscript a). It is worth noting that externalism faces the problem of stored beliefs too. According to externalism, a contingent feature of a subject's environment can affect her justification without affecting her mental life. But defenders of externalism think they can readily solve the problem. I challenge their attempt in Frise (manuscript b).
} 
A preliminary remark is in order. "The problem of stored beliefs" is an importantly infelicitous name. It seems there is in fact more than one relevant problem, or that there are underappreciated dimensions to the problem of stored beliefs. As stated so far, the problem concerns only doxastic justification, the justification of an attitude one has. In particular, the problem concerns the justification of doxastic attitudes that one has stored. But there are some propositions that are not before the subject's mind, propositions that the subject should, but does not, believe. And there are stored beliefs a subject should have and indeed has, but has for the wrong reasons. How does a theory of justification satisfactorily explain these should-claims? In other words, it is important to reflect also on a subject's propositional justification, her justification to have some attitude toward a proposition regardless of whether she in fact has the attitude or has it on the basis of her support. Sometimes, a subject has propositional justification for believing that $p$ but lacks doxastic justification, where $p$ is not before her mind. Consider:

\section{DESI}

Desi has a stored belief that fairies exist, and she has good enough reason to believe that they do: she remembers that her clearly trustworthy brother told her so. But what caused and currently sustains her belief that fairies exist is simply her desire that they exist. She has no relevant higher-order belief about how she has good reason to believe that fairies exist.

Because of its basis, Desi's stored belief that fairies exist is not doxastically justified (her belief is improperly caused, she has no suitable higher-order belief about it, or whatever). But Desi has propositional justification for believing that fairies exist. She would have this justification even if she did not believe that fairies exist. A theory of justification that does not account for this has a problem, even if it accounts for the doxastic justification of all of Desi's justified stored beliefs. The problem concerns the propositional justification one has for propositions not before one's mind. Call it the propositional problem of stored beliefs, and call the more familiar problem the doxastic problem.

Since doxastic justification requires propositional justification, the two problems largely overlap. Importantly, they are just instances of a more general problem: that of accounting for all justification concerning propositions not before the subject's mind. ${ }^{5}$ Even if a view solves the familiar doxastic problem, the general problem can remain. And a view is badly off if it cannot solve the general problem. The significance of this will become clear in the next section. For simplicity I often just discuss the more familiar problem.

\footnotetext{
5 "The problem of stored beliefs" is not fully apt in other ways. There is a problem if there is a single stored belief the justification of which is not explained. So, "beliefs" is misleading. And suspended judgment and disbelief can also be stored bearers of justification. To focus on the problem concerning just beliefs is not to exhaust the relevant problems. For simplicity, this paper sets these observations aside.
} 


\section{Epistemic Conservatism}

I will give three reasons for thinking that epistemic conservatism, even if true, does not solve the problem of stored beliefs for internalism. First I will explain the view. According to McGrath (2007: 14), epistemic conservatism is the view that "if one believes that $p$, then one is prima facie rational in retaining that belief." 6 One is justified in continuing to believe a proposition as long as one lacks reason to abandon belief. If Maria believes that dairy milk comes from cows, she is overall justified in retaining that belief if she has no defeaters-no reason to think that dairy milk does not come from cows, that her memory is especially defective, that she originally formed her belief for no good reason, and so on. Her having this justification does not require her to have, or to be disposed to have, an experience with memorial phenomenology that represents memory as generally accurate or represents dairy milk as coming from cows. And it does not matter whether Maria's belief is occurrent or stored. It still justifies her in retaining the belief.

Epistemic conservatism is typically understood to be a form of internalism and all its advocates advocate internalism. ${ }^{7}$ It suggests that beliefs justify, and beliefs are mental states, so it suggests that mental states justify. But epistemic conservatism states only a sufficient condition for having justification, not a necessary condition. For all that epistemic conservatives have said, non-mental differences could result in justificatory differences. Still, epistemic conservatism is compatible with internalism. It offers a resource some internalists utilize when accounting for the justification that many beliefs have via memory. ${ }^{8}$ The varieties of internalism compatible with epistemic conservatism could have a solution to the problem of stored beliefs. If they have one, it is false that the two minimal theses of internalism prevent it from solving the problem. Of course, epistemic conservatism is no help to the varieties of internalism it is incompatible with. If it solves the problem, perhaps we should reject those varieties.

Now, epistemic conservatism states a sufficient condition for justifiedly retaining a belief. Retains picks out a dynamic relation. It identifies a relation between objects over time. Epistemic conservatism states that a subject's having a belief at one time prima facie justifies the subject in having it a moment later. If the subject has the

\footnotetext{
${ }^{6}$ Cf. Harman (1986: Ch. 4) and McCain (2008: 186). In light of an objection, McGrath (2007: 21) eventually restates the view in a restricted form: If $\mathrm{S}$ believes that $p$, then $\mathrm{S}$ is rational to retain belief that p iff condition C obtains. McGrath (2007: 21 n. 39) expresses doubts about this formulation, and does not attempt to defend any particular interpretation of $\mathrm{C}$. In the absence of such an interpretation, the epistemic conservative solution to the problem of stored beliefs faces the first objection I will give above. And even in the presence of such an interpretation, the epistemic conservative solution still faces my other objections.

"Epistemic conservatism" may not be an ideal name for the view discussed in this section, since it sometimes refers to a genus of views, whose species include doxastic conservatism and phenomenal conservatism. Doxastic conservatism is the view that McGrath and others call "epistemic conservatism," and phenomenal conservatism is the view that if it seems to $\mathrm{S}$ that $p$, then $\mathrm{S}$ has prima facie justification for believing that $p$. Since I am primarily engaging McGrath here, I follow his terminology.

7 See e.g. McGrath (2007: 5), Poston (2014: 38-42).

8 See e.g. McCain (2008), McGrath (2007), and Poston (2016).
} 
belief a moment later, it is justified. Epistemic conservatism is thereby a theory of diachronic justification. More precisely, where $t_{1}$ and $t_{2}$ pick out successive times:

EC1. If $\mathrm{S}$ believes that $p$ at $t_{1}$, then $\mathrm{S}$ is prima facie justified in believing that $p$ at $t_{2}$.

EC2. If $\mathrm{S}$ believes that $p$ at $t_{1}$ and at $t_{2}$, then $\mathrm{S}$ 's belief at $t_{2}$ is prima facie justified.

EC1 states epistemic conservatism's sufficient condition for propositional justification (for simplicity I often drop the "prima facie"). EC2 states epistemic conservatism's sufficient condition for doxastic justification.

McGrath and other epistemic conservatives have not made the temporal parameters of their view formal, as EC1 and EC2 do. But McGrath (2007: 2) is clear that epistemic conservatism is a theory about justification as it pertains to the "dynamics of belief," not the "statics of belief." EC1 and EC2 make precise the dynamic temporal relation expressed by "rational in retaining." Since what the subject allegedly is rational in retaining is a belief, epistemic conservatism states not just a theory about propositional justification, but also theory about doxastic justification. Again, part of the appeal of epistemic conservatism is its alleged ability to account for the justification of the beliefs that memory preserves (especially in cases where one forgets one's original evidence). Epistemic conservatism is not a theory of synchronic justification, a theory about what at a time justifies belief at that time. This is for the best, because epistemic conservatism as a theory of synchronic justification, a theory about only $t_{1}$, seems false:

EC3. If $\mathrm{S}$ believes that $p$ at $t_{1}$, then $\mathrm{S}$ is prima facie justified in believing that $p$ at $t_{1}$.

EC4. If $\mathrm{S}$ believes that $p$ at $t_{1}$, then S's belief at $t_{1}$ is prima facie justified.

EC3 seems false because a belief does not seem to be self-supporting at a time. In fact, McGrath (2013: 245) agrees. Having a belief does not by itself support its content, although having had belief might support its content-it might be plausible that we should trust our past selves, other things being equal. And even if a belief could support itself, EC4 seems false. Arguably, in order for a belief to be doxastically justified, it must be caused by whatever justifies it. But a belief cannot cause itself at a time, just as a fire cannot cause itself at a time. At best a belief that $p$ at one time can cause a belief that $p$ a moment later, just as a fire at one time can cause a fire a moment later. EC1-EC4 exhaust the promising formalizations of epistemic conservatism. EC3 and EC4 fail to capture its dynamic character and seem false. Epistemic conservatism is best understood as EC1 and EC2. ${ }^{9}$

\footnotetext{
9 Cf. McCain (2008: 188), McGrath (2007: 17-18) and Poston (2014: 18), who are best read as endorsing $\mathrm{EC} 1$ and EC2. A theory placing a causal requirement on doxastic justification can still be internalist, if it states that mental features alone propositionally justify. For such an internalist theory, see McCain (2014: Chs. 5 and 6). Moon (2012a: 316), while granting that epistemic conservatism is true, questions whether a belief gains positive epistemic status by being based on itself, and questions whether in a specific case a belief is in fact based on itself. Unlike Moon, I question whether a belief can ever be based on itself at a time, and I specifically identify a causal problem for such synchronic basing.
} 
McGrath (2007: 21-22) thinks epistemic conservatism solves the problem of stored beliefs. The stored beliefs that we are inclined to count as justified are typically ones that we do not have overall reason to abandon. So, we are justified in retaining them. Epistemic conservatism seems to solve the problem, and no one has objected to it as a solution.

A first worry for epistemic conservatism as a solution to the problem of stored beliefs is that it seems to get DESI wrong. EC2 implies that Desi's stored belief that fairies exist is prima facie justified, since Desi had that belief a moment ago. The bad basis of her belief does not prevent it from being prima facie justified. EC2 states no constraints on the causes or sustainers of justified beliefs. As long as the subject still has a belief, it has justification now, regardless what sustains it. Unless Desi has some defeater for her belief, it is according to epistemic conservatism justified overall. But her belief is not justified overall.

The epistemic conservative could reply that there is a defeater for Desi's belief. McGrath (2007: 18) is fairly liberal about defeating conditions: "defeaters, possessed or not, which are 'constructible' from one's current perspective, are potential defeating conditions". But even if we grant this view about defeating conditions, it is implausible that there must be a defeater constructible from Desi's perspective. It is rarely clear from one's current perspective what originally caused or now sustains any of one's beliefs, even when one's good reasons caused and sustain one's beliefs. We can stipulate that Desi cannot tell that her fairy belief is based on desire, and so she lacks the materials to construct a defeater. Consequently, epistemic conservatism counts her unjustified stored belief that fairies exist as justified full stop. Epistemic conservatism fails to solve the problem of stored beliefs. $^{10}$

Second, while EC2 can account for the justification of a subject's belief that $p$ at $t_{2}$, it does not thereby account for the justification of the subject's belief that $p$ at $t_{1}$. This is a problem because not all possible justified stored beliefs are believed at some earlier time. Consider:

VIC

Vic is a victim in a memorial skeptical scenario. An evil demon popped Vic into existence at noon today-he did not exist until then. At noon Vic's mental states are identical to Ric's. Ric came about in the ordinary way, long before noon. He believes many things and has many apparent memories. Vic, being Ric's mental twin, believes the same things and has the same apparent memories. Many of these beliefs are justified and stored. ${ }^{11}$

\footnotetext{
${ }^{10}$ McGrath (2013: 245) independently notes that cases like DESI threaten epistemic conservatism. He thinks they are potential counterexamples to his theory. (For that reason, in personal correspondence, he found EC1 more attractive than EC2). It is worth emphasizing that even if they are not counterexamples, they show that epistemic conservatism fails to solve the problem of stored beliefs. It is also worth noting that epistemic conservatism and dispositionalism (see Sect. 3) are silent on how it is that stored suspended judgment can be justified. These views need to be expanded in order to account for this justification.

11 VIC resembles a case developed by Bertrand Russell and discussed by Frise (2015), Huemer (1999: 350-352), and Moon (2012b: 352-357), a case in which the world came about only 5 min ago and nearly all beliefs about the past are false. However, VIC differs importantly from Russell's case. VIC focuses on justification at the moment of creation, not $5 \mathrm{~min}$ after. Epistemic conservatism more easily accounts for
} 
There is no reason to doubt that VIC is possible. Victims in memory skeptical scenarios seem able to have stored beliefs when they come into existence, and it seems that many of these beliefs could be justified, especially when the victims have mental twins with many justified stored beliefs. What's more, internalism is often motivated by the 'new evil demon problem', which centers on a structurally parallel case to VIC but which concerns external-world skeptical scenarios, not memory skeptical scenarios. Internalists will have special reason to grant that VIC is possible.

VIC, if possible, reveals that epistemic conservatism poorly solves the problem of stored beliefs. Since Vic does not exist before noon, he of course does not believe anything prior to noon. So, Vic has no antecedent beliefs which could explain the justification of any of his stored beliefs at noon. McGrath mistakenly supposes that for every justified stored belief that $p$, there is a prior belief that $p$. But a belief, justified or not, can be stored even if it has not been previously held. A belief is stored so long as it is not before the subject's mind. EC2, even if true, does not solve the problem of stored beliefs. To be clear, the basic reason is this. Epistemic conservatism is just a thesis about justified belief retention, not about justified belief formation. It does not account for the justification of any belief that is stored directly at the time of its formation.

One might reply as follows. If a subject's belief that $p$ is doxastically justified, then the belief is caused by that which justifies the subject in believing that $p$. And causation always takes time. Whatever it was that brought about Vic's beliefs at noon, it was not something that justified him in believing that $p$ a moment before. Since Vic did not exist until noon, prior to noon nothing justified him in believing anything. Vic's beliefs at noon are therefore not caused by their justifiers, and so they are not doxastically justified at noon. So, VIC does not reveal that there are justified stored beliefs which epistemic conservatism cannot account for.

I will grant that causation always take time, although this thesis does face objections. VIC still introduces trouble for epistemic conservatism as a solution to the problem of stored beliefs. For EC1 does not explain Vic's propositional justification at noon. We can grant that Vic has no justified stored beliefs at noon, since none of his beliefs are at noon based on his justification. But it is plausible that at noon Vic is justified in believing many things, including the contents of some of his stored beliefs. Yet EC1 does not credit Vic as having justification for believing anything he believes. The antecedent of EC1 is not satisfied, since Vic did not exist a moment before noon. Epistemic conservatism fails to solve the propositional problem of stored beliefs. Of course, McGrath might have proposed only that epistemic conservatism could solve the doxastic problem. But if it cannot also solve a closely related instance of the more general problem, internalism remains badly off.

This may tempt us to understand epistemic conservatism as stating EC3 after all. According to EC3, at any time, S's believing that $p$ prima facie justifies $\mathrm{S}$ in

Footnote 11 continued

the justification of stored beliefs at the latter time than at the former. Frise (manuscript b) presents a case like VIC as a problem for preservationism, the view that memory preserves the justification of the beliefs it preserves. 
believing that $p . \mathrm{S}$ at any time has prima facie justification for anything she believes then. Because Vic has stored beliefs at noon, he would at noon have justification for believing the contents of all his stored beliefs. Above I noted that EC3 does not capture the temporal character of retains and that EC3 seems false, but let's set these details aside. EC3 still does not ultimately help with the propositional problem of stored beliefs presented by VIC. Suppose Ric at noon fails to believe some proposition $q$ that he has justification for believing and that is not before his mind. Since Vic is Ric's mental twin, internalism entails that he too is justified in believing that $q$ at noon. EC3 (and EC1, for that matter) fails to account for either subject's justification for believing that $q$-by stipulation, at noon neither subject has a belief that $q$ which could provide this justification. Yet accounting for this justification is part of the propositional problem of stored beliefs. So EC3, even if true, does not solve the problem.

Here is my final objection to epistemic conservatism as a solution to the problem of stored beliefs. As we have seen, epistemic conservatism (understood as just EC1 and EC2) does not count Vic as having justification for believing the contents of any of his stored beliefs at noon. If epistemic conservatism is a complete solution to the problem of stored beliefs-if it tells the full story of the justification of our stored beliefs - then Vic is unjustified in believing the contents of all of his stored beliefs at noon. But according to EC1, a moment after noon, Vic is prima facie justified in believing the contents of all stored beliefs he had at noon. We can stipulate that none of Vic's mental states, conditions, or events change between noon and a moment after noon. He has no new memories a moment after noon. We can even stipulate that there is no intra-mental causal connection between Vic's mental states at these times; Vic's mental life a moment after noon is not caused by his mental life at noon, but rather is caused by whatever brought about his mental life at noon. A moment after noon, his noon beliefs give him justification he lacked at noon. So, Vic is mentally identical to himself at these two times, but his justification is not identical. Thus epistemic conservatism, if we do not supplement it with some account of Vic's noon justification, unexpectedly denies internalism. ${ }^{12}$ Consequently, it would not solve the problem of stored beliefs for internalism! And, of course, if we do supplement epistemic conservatism with an account, then it is not by itself a solution to the problem of stored beliefs.

Contra McGrath, even if epistemic conservatism is true, it does not solve the problem of stored beliefs. The three reasons for believing this may even refute epistemic conservatism. I will not argue here that they do. But they do undermine epistemic conservatism considerably, since one of its main alleged assets is that it accounts for our justification that concerns memory. ${ }^{13}$

\footnotetext{
12 At least, epistemic conservatism would deny what some philosophers (e.g., Goldman (2009: 327-328)) understand as "traditional" internalism. On traditional internalism, a subject's mental life just at a time, and not also her mental history, determines her justification at that time. Epistemic conservatism remains compatible with an untraditional internalism, on which a subject's mental history matters for her justification. Huemer (1999: 351-352) defends this variety of internalism, and I challenge it in Frise (manuscript b); cf. Moon (2012b: 352-354).

13 McCain (2008), McGrath (2007), and Poston (2016) claim that epistemic conservatism has this asset.
} 


\section{Dispositionalism}

\subsection{Dispositionalism Defended}

Several internalists have defended some version of a view that I will call dispositionalism:

If $\mathrm{S}$ has disposition $\mathrm{X}$, then $\mathrm{S}$ is prima facie justified in believing that $p$.

Dispositionalism is a schema. Different versions of it assign different interpretations to $\mathrm{X}$. On all versions, having a disposition of a certain sort justifies believing a related proposition. Dispositionalists have tried to solve the problem of stored beliefs. ${ }^{14}$ A disposition pertaining to memory can justify a stored belief, they claim, even when the disposition is not manifest.

In this section I state the most recent and promising dispositionalist attempt to solve to the problem-namely, Conee and Feldman's (2011: 303-305) attempt. I also show that Senor's (2009) and McGrath's (2007) objections to the dispositionalist attempt fail. In the next section, I improve Conee and Feldman's dispositionalist attempt. Finally, in the section after, I develop two new arguments showing that even the improved attempt is unsuccessful.

Conee and Feldman fill out dispositionalism as follows:

DR. If $\mathrm{S}$ has a disposition to recollect $p$, then $\mathrm{S}$ is prima facie justified in believing that $p .{ }^{15}$

A disposition to recollect $p$ is a disposition to recall $p$ as known, not simply as believed. Having this disposition does not require $p$ to be true, much less known. If the disposed recollection is strong and clear enough, and undefeated, it justifies strongly enough for knowledge. Conee and Feldman (2011: 304) say, of a subject who has learned a proposition and at noon not forgotten it, that "one aspect of his noontime mental condition makes it true that he is able to recall the proposition." A subject has a recollective disposition toward $p$ when she has learned and has not forgotten that $p$, where 'learned' is non-factive. That is:

$\mathrm{LNF}$. If $\mathrm{S}$ has learned and not forgotten $p$, then $\mathrm{S}$ has a disposition to recollect $p$.

Conee and Feldman do not say exactly how they mean forgotten, so it is not fully clear what learning and not forgetting amounts to. But they (2011:305) note that in normal cases, a subject's recollective disposition "exists by its having been formed in the past when a proposition was learned, or at least when the proposition seemed to have been learned, and then retained by a process of long-term memory consolidation." And learned is best understood broadly here, since Conee and

\footnotetext{
${ }^{14}$ See Audi (1995: 37), Conee and Feldman (2011: 303-305), Ginet (1975: 154-157), and Piazza (2009). Cf. Conee and Feldman (2004: 236-237). For variations on this attempt, see Conee and Feldman (2004: 67-69), Madison (2014: 49-50), and McCain (2014: 148-149).

15 Conee and Feldman describe recollective dispositions as defeasible, justifying evidence. For simplicity I omit talk of evidence, and I mostly talk about prima facie justification rather than defeasible justifiers. Nothing hangs on this. In correspondence, they have confirmed that LNF (below) is part of their view.
} 
Feldman allow that recollective dispositions can come about via "brain malfunction or tampering," and that the disposition still defeasibly justifies, "whatever its historical origins."

I will call the conjunction of DR, LNF, and Conee and Feldman's account of a recollective disposition Conee and Feldman's dispositionalism. How might their dispositionalism solve the problem of stored beliefs? They (2011: 304) suggest that ordinarily a subject with a justified stored belief that $q$ "has the potential to bring $q$ to mind with the phenomenology of activating a memory, specifically, the memory that $q$." The subject has a disposition to recollect $q$. Conee and Feldman's dispositionalism seems able to account for the propositional and doxastic justification relevant to the problem of stored beliefs.

Senor (2009) and McGrath (2007) apparently object to any form of dispositionalism as a solution to the problem of stored beliefs. ${ }^{16}$ But Conee and Feldman's dispositionalism, I argue, is safe from their objections. Senor (2009) says, regarding the problem of stored beliefs:

This problem might be thought resolved by appealing to counterfactuals or dispositions. That is, a stored belief might be thought to be prima facie justified iff were this belief to become occurrent, it would be accompanied by the appropriate memory image or seeming. Yet this condition is pretty clearly false. The phenomenology of recollection depends crucially on the context in which the belief is recalled. Typically, the experience one has when one recalls a belief depends at least on how the recollection was cued, how much attention one is currently paying to the recalled belief, and what other beliefs are then occurrent.

The objection to the dispositionalist solution seems to be that DR is false: a recollective disposition does not justify. Senor assumes that a disposition is analyzable in terms of a counterfactual conditional that involves a particular stimulus condition. The relevant stimulus condition is the justified stored belief's becoming occurrent. Senor supports his objection by denying that, in this condition, the subject would have a justifying memory experience. This is because the phenomenology of actual recollection is importantly sensitive to contextual factors. In some contexts, the subject would have justifying phenomenology, but not in others. Since mere recollection does not justify, a mere recollective disposition does not either. If Senor's objection is correct, Conee and Feldman's dispositionalism does not solve the problem of stored beliefs.

It is worth noting that the defender of Conee and Feldman's dispositionalism need not grant Senor's conditional analysis of dispositions. It is difficult to state well what a disposition is, and the conditional analysis is at best highly controversial. We are free to pick an alternative analysis or to suppose that there simply is no analysis. We can understand a disposition as we do pre-analytically, and think of a disposition to recollect $p$ as similar to one's values, or moods, or character traits,

${ }^{16}$ Goldman (1999) does as well, but his objections only threaten a form of dispositionalism that Conee and Feldman (2011) do not endorse. Since Senor and McGrath identify no particular form of dispositionalism as their target, their objections seem intended for all forms. 
like shyness or irritability or generosity. It is much easier to recognize that someone values honesty than it is to find a true counterfactual that corresponds to her valuing honesty. And, even if we accept a conditional analysis, we are free to identify a much broader stimulus condition than Senor does.

Still, even if we grant Senor's assumptions, the support for his objection is inadequate. His support is that a subject's circumstances crucially determine the phenomenology of her recollective experience. The 'what it's like' aspect of memory experience is importantly context-sensitive. But phenomenology that is importantly context-sensitive need not relevantly vary. And it is not clear that recollective phenomenology relevantly varies. True, it varies in strength and in degree of familiarity. In some contexts the memorial phenomenology a subject has while recollecting $p$ is more vivid, and in other contexts less. But in all these contexts the same content is presented to the subject with some memorial phenomenology - the proposition is brought to mind with, as Conee and Feldman put it, "the phenomenology of activating a memory". Even though the phenomenology of actual recollection is context-sensitive, it appears sufficiently invariant to justify invariantly. So this is not a good reason to deny that the recollective disposition justifies. Senor's objection may be correct, but it lacks support.

McGrath (2007: 11) resists dispositionalist solutions for a different reason. He claims that "One might have the disposition [to enjoy memorial phenomenology] without having any [justifying] evidence at all." He tries to illustrate this with an example like the following:

\section{FARGO}

Fargo has forgotten his childhood home phone number. But he is disposed, when asked precisely about it, to undergo memorial phenomenology regarding it. If asked "Is it true that your childhood home phone number was xxx?", Fargo would recall that it was xxx. ${ }^{17}$

McGrath concludes that "In such a situation, before being asked, one is not rational to believe that $p$. And so one's being disposed...must not be a way of having the [justifying] evidence." His point seems to be that dispositionalism would yield too much justification. One could in very particular circumstances be disposed to recollect that $p$, and therefore, unintuitively, count in all circumstances as justified in believing that $p$. A dispositionalism like Conee and Feldman's attributes justification where there is none.

However, FARGO reveals no flaw in a dispositionalist solution. FARGO stipulates that Fargo has forgotten that his childhood home phone number (hereafter his number) was xxx. On Conee and Feldman's dispositionalism, the sufficient condition for having a recollective disposition is: learning and not forgetting. Their dispositionalism does not imply that Fargo has a disposition to recollect that his

\footnotetext{
17 The details of FARGO are from McGrath (2007: 11). I've named the case and its subject. McGrath uses FARGO to present an objection that he says is Goldman's (1999: 278-279). But FARGO improves the case Goldman uses. In Goldman's, the subject's relevant disposition involves information that the subject has never possessed, so it is doubtful that the subject has a disposition to recollect that information. So I discuss only FARGO.
} 
number was xxx. So, their dispositionalism does not attribute to Fargo justification for believing that his number was xxx.

Similarly, FARGO stipulates that Fargo is disposed to recollect that his number was $\mathrm{xxx}$ when he is asked about it. It does not follow that he has a disposition to recollect that his number was xxx. If $\mathrm{S}$ is disposed to do $\mathrm{A}$ in some circumstances $\mathrm{C}$, it does not follow that $\mathrm{S}$ is disposed to do A simpliciter. There is no reason to suppose that Fargo, prior to being asked about his number, has a disposition to recollect it. So there is no reason to suppose that on dispositionalism he, prior to being asked about his number, is justified in believing it was xxx. Further, once Fargo is asked, it is not implausible that he is justified in believing it was xxx.

I have claimed that FARGO fails to challenge Conee and Feldman's dispositionalism because Fargo does not satisfy LNF. FARGO stipulates that Fargo has forgotten his number. There are of course stronger and weaker senses of forgotten (and its cognates). If my claim is correct, McGrath must mean forgotten in a sense strong enough that prevents Fargo from having a recollective disposition. McGrath does not say what he means by the term, but his use is consistently strong. As he uses the term, it seems one typically does not have a recollective disposition toward what one forgets. McGrath uses forgotten to describe evidence that "plays no current role in the sustaining" of belief (6), evidence that contrasts the evidence we "have" (9), and evidence that one can no longer "provide" (9). He also uses it to describe a whole episode of events that one, by taking a pill, has totally erased from one's memory (22). In McGrath's use of the term, it seems, one is unable to recall what one forgets, and normally what one forgets is not retained by a process of longterm memory consolidation. As McGrath talks of forgetting, Fargo's forgetting prevents him from having the relevant recollective disposition. As a result, FARGO provides no reason to think that Conee and Feldman's dispositionalism attributes justification where there is none. McGrath's objection is unsuccessful.

\subsection{Dispositionalism Developed}

I now offer two improvements for Conee and Feldman's dispositionalism that position it better to solve the problem of stored beliefs. Each improvement calls for a broader understanding of recollective disposition.

First, Conee and Feldman identify a recollective disposition that $p$ as a disposition to recall $p$ as known. To recall $p$ as known is to have an experience with the phenomenology of, among other things, consciously knowing that $p .{ }^{18}$ But given this view of a recollective disposition, LNF looks false. LNF says that a subject who has learned and not forgotten $p$ has a disposition to recollect $p$. But it's not true that we are disposed to have an experience with the phenomenology of consciously knowing just anything that we have learned and not forgotten. We learn certain things simply by coming to have just some justification for believing them. When we do not forget these things, we are not thereby disposed to have experiences with the phenomenology of consciously knowing them. Instead, we are disposed to have experiences with a weaker sort of phenomenology.

18 Conee and Feldman endorsed this reading of 'as known' in correspondence. 
Further, suppose it's true that by learning and not forgetting a proposition, one is disposed to recall it as known. It seems that this disposition would provide one with more than just some justification for believing the proposition-after all, one is disposed to have an experience with the phenomenology of knowing it. So, if $\mathrm{S}$ learns that $p$ by acquiring just some justification for believing that $p$, it seems that $S$ 's justification would increase if $\mathrm{S}$ simply does not forget $p$. Perhaps memory sometimes boosts justification, but it does not boost it in this way. Fortunately, there is a broader understanding of recollective dispositions that will avoid all these troubles and introduce no others. Although we do not seem disposed to recall as known just anything that we have learned and not forgotten, we do seem disposed to recall each of these things as true. And being disposed to recall $p$ as true seems to justify believing that $p$. Conee and Feldman's dispositionalism seems more promising if a recollective disposition is a disposition to recall as true or as known.

Second, in some cases where $p$ is not before the subject's mind, it seems the subject has justification for believing that $p$ yet lacks a disposition to recall $p$ as true or as known. Philosophers and psychologists of memory standardly endorse a tripartite distinction regarding types of memory systems: semantic (memory for a proposition), episodic (memory for an experienced event), and procedural (memory for skill or of how to perform an action). ${ }^{19}$ Conee and Feldman's dispositionalism counts certain dispositions that are a part of semantic memory as justifying. They think the justifying dispositions dispose subjects to have certain experiences with propositional content. But semantic memory alone will not solve the problem of stored beliefs. I will argue that certain justifying dispositions are a part of episodic memory. Episodic memory enables a re-experiencing of events as experienced before. Being disposed to recall a set of experienced events that are suitably related to $p$ justifies believing that $p$, even in the absence of a disposition to recall $p$ itself. Consider:

\begin{abstract}
BUSTER
Buster is justified in believing that he took the bus today. But he isn't disposed to recall that as true. Rather, his episodic memory disposes him to have experiences that justify his believing it. Buster is inclined to activate with memorial phenomenology first-person experiences of his bus ride-memorial imagery of passengers seated nearby, of trees whizzing in the windows; a memorial olfactory experience of the smoker beside him; a memorial auditory experience of the bus droning beneath him. He is inclined to feel these experiences as connected in a certain temporal order with other experiences. ${ }^{20}$
\end{abstract}

Buster is not disposed to recall that he took the bus today. He is instead disposed to recall many experiences that support believing that proposition. Now, one might think that, unless Buster consciously associates those experiences with the proposition, the (disposition to have the) experiences cannot justify him in

\footnotetext{
19 Philosophers and psychologists use various terms to make more or less the same distinction. In psychology, Tulving (1982) popularized the semantic/episodic memory distinction. In contemporary philosophy, Russell (1921/1995) and Martin and Deutscher (1966) influentially discuss episodic memory, and John Locke talks about it even earlier.

${ }^{20}$ For discussion of a similar case see Madison (2014: 39-40).
} 
believing the proposition. But this seems to over-intellectualize things. When a subject does not consciously associate her recalling $p$ with $p$, her recalling still justifies believing that $p$. It is hard to see why it would be different when the subject recalls experiences that support $p$. Conee and Feldman's dispositionalism is more promising if, on it, dispositions to recall events as experienced by the subject count as recollective, and therefore as justifying. Cases like BUSTER seem common, and a solution to the propositional problem of stored beliefs must account for them.

Similarly, semantic memory seems to justify some stored beliefs, but not always by disposing us to recall the content of these beliefs as true or known. Consider:

GIL

Gil has a stored belief that (i) he swam in the Gulf of Mexico. He is disposed to recall as true that (ii) he swam at a beach in Pensacola, Florida, and that (iii) Pensacola beaches are on the Gulf of Mexico. But he is not disposed to recall as true that he swam in the Gulf of Mexico. Rather, he is disposed to infer it automatically upon recalling (ii) and (iii).

It seems Gil's stored belief is ultimately justified by some of his dispositions. By recalling (ii) and (iii), it will become clear to Gil in a memorial way that he swam in the Gulf of Mexico. A disposition to recall a set of propositions other than $p$ seems able to justify believing that $p$. One might object that Gil must think about (ii) and (iii), or consciously associate them with (i), in order for his inference to justify believing (i). But, again, this seems to over-intellectualize matters.

In sum, Conee and Feldman's dispositionalism is more promising if we understand recollective disposition more broadly. Each of the following should count as a recollective disposition toward $p$ : (a) a disposition to recall $p$ as known, (b) a disposition to recall $p$ as true, (c) a disposition to recall experienced events that jointly and clearly indicate that $p$, and (d) a disposition to recall a set of propositions that jointly and clearly indicate that $p$.

\subsection{Dispositionalism Indisposed}

I will now offer two arguments that show that Conee and Feldman's dispositionalism still does not solve the problem of stored beliefs. Given the support for my arguments, it is unclear whether their dispositionalism can be improved further.

First, Conee and Feldman's dispositionalism attributes too much justification. Recall that LNF states a sufficient condition for S's having a recollective disposition toward $p$ : S's having learned and not forgotten $p$. However, there is considerable psychological research suggesting that we forget far less than we are inclined to think we do. In fact, very little that we learn and store in long-term memory is ever forgotten. ${ }^{21}$ Rather, it is just not always directly accessible, and this can mislead us into thinking it is totally inaccessible. We retain the information and can retrieve it

\footnotetext{
${ }^{21}$ Koutstaal and Schacter (1997) review the psychological research on this. Cf. Wagenaar (1986). Bjork and Vanhuele (1992: 156) go so far as to claim that any information that makes it into long-term memory remains there "essentially forever". For philosophical discussion, see Michaelian (2011a: 402-404).
} 
if cued properly. If this psychological data is roughly accurate, then Conee and Feldman's dispositionalism attributes too much justification. A case illustrates this:

\section{MARGO}

Margo learned and has not forgotten her childhood home phone number. If asked "Is it true that your childhood home phone number was Xxx?", Margo would recall that it was xxx. But if merely asked "What was your childhood home phone number?", Margo would not recall it. And if merely asked "Can you recall your childhood home phone number?", Margo would not recall it. In fact, she is disposed to seem to herself unable to recall the number.

Since Margo learned and has not forgotten her childhood home phone number (hereafter, her number), Conee and Feldman's dispositionalism implies that she is disposed to recollect it, and that she is therefore prima facie justified in believing that it was xxx. Unlike Fargo and his number, Margo has not forgotten her number, in McGrath's strong sense of forgotten. She retains her number in her long-term memory, a (relation to a) representation of her number sustains some memory or belief for her, Margo still "has" her number, and her number has not been erased from her memory. She can count as having a recollective disposition.

However, it is plausible that until Margo recalls that her number was xxx, Margo is overall justified in suspending judgment on whether it was xxx. Although Margo's number is available to her via her memory, to her it would seem otherwise. She is disposed to seem unable to access the number. Ordinarily, if a subject seems to herself unable to access anything as the correct view on a matter, then she is not justified in believing any particular view on the matter. Instead, she is justified in suspending judgment about (or sometimes disbelieving-I'll omit this option for simplicity) any particular view. Now, Margo is disposed to seem unable to access her number. This obstructive disposition should count in favor of suspending judgment, if a recollective disposition counts in favor of believing. It would be odd if dispositions to recollect were the only dispositions that affected justification; and the attitude that a manifest disposition supports reveals the attitude the disposition supports. So, it is plausible that if Margo is disposed to seem unable to access her number, she is justified in suspending judgment on each particular view about it, including that it was xxx. Learning and not forgetting seems to matter little if, from one's perspective, it's as if one never did learn or as if one did forget. If Margo has no defeater for the prima facie justification that Conee and Feldman's dispositionalism attributes to her, their dispositionalism incorrectly implies that she is overall justified in believing her number was xxx.

One might think Margo does have a defeater. Her disposition to seem unable to recall her number supplies it. To her, it would seem that there is no number that she can recall as hers. This gives her reason to doubt that she is disposed to recollect her number. Perhaps this somehow defeats any justification her recollective disposition provides. She is not overall justified in believing her number was xxx, so Conee and Feldman's dispositionalism has no incorrect implication here.

But, assuming Margo has a defeater, suppose it is blocked. A clearly trustworthy expert on the matter (say, Margo's childhood friend, a cognitive psychologist) testifies to Margo that there is a number that she can recall as her number. This 
testimony could rationally persuade Margo that her apparent inability to recall her number is misleading (even though, try as she might, Margo still does not recall her number). In that case, Margo's alleged justification from her recollective disposition would be undefeated. But it doesn't appear that Margo, after hearing the testimony, should then believe her number was xxx. She still seems to herself unable to recall her number, and the testimony gives her no hint as to what it was. Until she recalls some particular number, believing any would to her be arbitrary. Conee and Feldman's dispositionalism incorrectly implies that Margo is overall justified in believing it was xxx.

It might seem that we could satisfactorily revise Conee and Feldman's dispositionalism and avoid this objection. The most promising revision limits the kinds of recollective dispositions that justify. Perhaps dispositions vary in strength. It could be that all justifying recollective dispositions are stronger than Margo's disposition to recollect her number. If that is correct, a revised dispositionalism does not imply that Margo is prima facie justified in believing that her number was xxx.

This revised dispositionalism revises DR and LNF. A recollective disposition justifies only if it is strong enough. But how strong is strong enough? And how do we suitably modify the antecedent of LNF? I see no good answers. We could try something like:

$\mathrm{LNF}^{*}$. If $\mathrm{S}$ has learned and has not forgotten $p$, and $p$ is easily mentally accessible to $\mathrm{S}$, then $\mathrm{S}$ has a strong disposition to recollect $p .^{22}$

But 'is easily mentally accessible to' is a dispositional relation. Exactly when does and doesn't it obtain? The answer is insufficiently clear; we cannot tell whether the revised dispositionalism solves the problem of stored beliefs without attributing too much justification. Consider Margo and her number. Isn't it as mentally accessible to her as some contents of our justified stored beliefs are to us? It is hard to defend a "No" answer. One defense notes that our access would be quicker than hers. But Margo's number is quickly accessible to her, when she is suitably prompted. Another defense notes that for us there are more diverse suitable prompts than there are for her - a broader range of circumstances in which there is mental access. But supposing that is true, why would it matter? The strength of a disposition is not a mere function of the breadth of circumstances in which the disposition is manifest. A disposition is not weakened by being masked. (A bubble-wrapped vase is no less fragile).

Conee and Feldman's dispositionalism attributes justification where there is none, and there is no clear, appropriate revision to LNF that avoids this result. And LNF, even if appropriately revised, faces another problem: it seems false in light of research from cognitive psychology. This is the second problem for Conee and Feldman's dispositionalist solution. That $\mathrm{S}$ has learned and not forgotten $p$ is indeterminate with respect to whether $S$ has a disposition to recollect $p$. My objection and support differ importantly from Senor's. Senor in effect denies DR (i.e., that recollective dispositions justify) because the phenomenology of recollection is importantly context-dependent. He thinks that a recollective disposition

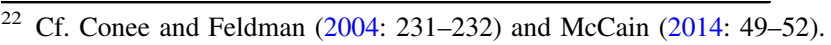


toward $p$ underdetermines whether the recollective phenomenology will justify believing $p$. I do not deny DR. Because recollective phenomenology seems relevantly invariant, recollection and recollective dispositions might justify. I claim however that the content we are disposed to recollect is in a relevant way independent of or underdetermined by what we have learned and not forgotten. So it is not clear that we have the all of the right recollective dispositions, the ones required for Conee and Feldman's dispositionalism to solve the problem of stored beliefs.

Research in cognitive psychology strongly supports my objection. The prevailing view among psychologists is that the content of recollection is not a function solely of what is stored in memory. The context in which the subject retrieves what is stored matters considerably; several kinds of features of the retrieval context contribute to what the subject recalls, in some surprising ways. These features not only partially determine what is retrieved, but also add to it. Let content alteration at retrieval pick out this phenomenon. I claim that the content alteration that occurs at retrieval is such that LNF is false. S's learning and not forgetting $p$ underdetermines whether $\mathrm{S}$ is disposed to recollect $p$. What's more, $\mathrm{S}$ 's learning and not forgetting any set of propositions underdetermines whether $\mathrm{S}$ is disposed to recollect $p$-a subject's network of stored information does not fix her recollective dispositions.

Of the many features of the retrieval context that result in content alteration, I will mention just three: the cue that prompts recollection, the related information the subject has recently retrieved or learned, and the retrieved content itself. Cues can add substantive details to what the subject retrieves (if, e.g., the cue "leads the witness"), and can determine whether seemingly lost details are retrieved (if, e.g., the cue involves visualizing an experienced event, or visualizing a series of events in various orders). ${ }^{23}$ Often, recollecting $p$ suppresses recollections related to $p$, learning $p$ leads to mistaken recollections about what else one has recently learned, and thinking about something causes us to incorporate it into a recollection. ${ }^{24}$ And the amount of detail in what we retrieve affects what we represent as its source during recollection. ${ }^{25}$ In light of phenomena like these, psychologists generally hold that memory is generative as a rule, not as an exception. ${ }^{26}$ That is, normal recollection is a content-creating rather than content-preserving process.

The above suggests that LNF is false. The content of what we recollect thoroughly depends on our particular retrieval circumstances, not just on what is stored and retrieved. We are, of course, disposed to employ during memory experiences information related to what we have learned and not forgotten. But we

\footnotetext{
${ }^{23}$ Michaelian (2011b) and Schacter (2002: Ch.5) discuss the first phenomenon, and Fisher and Edward (1992) and Schacter (2002: 119-120) discuss the second. Notably, police questioning methods have changed in light of what psychologists have discovered here.

24 Respectively, see Bjork and Vanhuele (1992: 156); Roediger and McDermott (1995) and Schacter (2002: 98); and Kelley and Lindsay (1993).

25 See Mitchell and Johnson (2000).

26 For arguments that memory is generative yet reliable, see Michaelian (2011b). For arguments that it is evolutionarily adaptive that memory is generative, see Bjork and Vanhuele (1992), Michaelian (2011c), and Schacter (2002).
} 
are not in general disposed to represent, during these experiences, precisely what we learned and have not forgotten. Rather, what is stored interacts with features of the retrieval context, resulting in an output representation. Whether the output matches what was learned is determined in part by these features. These features are not interfering with the normal functioning of recollection, as if recollection would otherwise yield an output that matches what was learned. The features are normal inputs to recollection. Eliminate these features, and it becomes unclear what, if anything, we would recollect. But if that is so, then the fact that $\mathrm{S}$ has learned and not forgotten $p$ underdetermines whether $\mathrm{S}$ is disposed to recollect $p$. We should reject $\mathrm{LNF}$.

Memory processing is complicated, and the rich psychological research on it leaves much unexplored. We do not yet have a sense of exactly what disposes us to recollect precisely what we're disposed to recollect. So there is no clear, good substitute for LNF. In the absence of a good substitute, we cannot test the implications of Conee and Feldman's dispositionalism against our intuitive judgments about justification. So it does not solve the problem of stored beliefs.

It might seem that LNF is a dispensable feature of Conee and Feldman's dispositionalism. We can simply let our guide be our ordinary judgments about who is disposed to recollect what. By combining these judgments with DR, Conee and Feldman's dispositionalism has the desired implications. However, ordinarily, it is far from clear just which recollective dispositions a subject has. In any event, it is typically clearer that a subject has (or lacks) a justified stored belief than it is that a subject is disposed to recollect its content. Our intuitions about recollective dispositions inadequately play LNF's role. Of course, for hypothetical cases we can stipulate which dispositions a subject has. But we cannot do so for actual cases, yet we need to test Conee and Feldman's dispositionalism against actual cases.

\section{Conclusion}

The internalist attempts to solve the problem of stored beliefs are unsuccessful. Epistemic conservatism attributes both too much and too little justification. And the most promising form of dispositionalism attributes too much justification yet also has too few testable implications. This appears to leave internalism in an uncomfortable position; it may face a crucial problem it cannot solve, and a key argument for internalism (namely, that it gets the cases right) may fail. I do not think internalists should despair, however. As I argue in Frise (manuscript a), there is a plausible solution to the problem available both to internalists and to externalists.

Acknowledgements For helpful comments and conversation on a draft of this paper, I thank Earl Conee, Richard Feldman, Kevin McCain, Matthew McGrath, Andrew Moon, Thomas Senor, an audience at the 2015 Alabama Philosophical Society Conference, and two anonymous referees. I revised this paper while supported by a grant from the Templeton Religion Trust. The opinions expressed in this paper are my own and do not necessarily reflect the views of the Templeton Religion Trust. 


\section{References}

Audi, R. (1995). Memorial justification. Philosophical Topics, 23(1), 31-45.

Bjork, R., \& Vanhuele, M. (1992). Retrieval inhibition and related adaptive peculiarities of human memory. NA-Advances in Consumer Research, 19, 155-160.

Conee, E., \& Feldman, R. (2004). Evidentialism: Essays in epistemology: Essays in epistemology. Oxford: Oxford University Press.

Conee, E., \& Feldman, R. (2011). Replies. In T. Dougherty (Ed.), Evidentialism and its discontents. Oxford: Oxford University Press.

Frise, M. (2015). Epistemology of memory. In J. Fieser \& B. Dowden (Eds.), The Internet Encyclopedia of Philosophy. http://www.iep.utm.edu/epis-mem/.

Frise, M. (manuscript a). Eliminating the Problem of Stored Beliefs.

Frise, M. (manuscript b). Preservationism in the Epistemology of Memory.

Fisher, R. P., \& Edward, R. (1992). Memory-enhancing techniques for investigative interviewing: The cognitive interview (Vol. xi). Springfield, IL: Charles C Thomas, Publisher.

Ginet, C. (1975). Knowledge, perception, and memory (Vol. 26). Dordrecht: D. Reidel Pub. Co.

Goldman, A. I. (1999). Internalism exposed. Journal of Philosophy, 96(6), 271-293.

Goldman, A. I. (2009). Internalism, externalism, and the architecture of justification. Journal of Philosophy, 106(6), 309-338.

Goldman, A. I. (2011). Toward a synthesis of reliabilism and evidentialism? Or: Evidentialism's troubles, reliabilism's rescue package. In T. Dougherty (Ed.), Evidentialism and its discontents. Oxford: Oxford University Press.

Harman, G. (1986). Change in view. Cambridge: MIT Press.

Huemer, M. (1999). The problem of memory knowledge. Pacific Philosophical Quarterly, 80(4), 346-357.

Kelley, C. M., \& Lindsay, D. S. (1993). Remembering mistaken for knowing: Ease of retrieval as a basis for confidence in answers to general knowledge questions. Journal of Memory and Language, 32(1993), 1.

Koutstaal, W., \& Schacter, D. L. (1997). Inaccuracy and inaccessibility in memory retrieval: Contributions from cognitive psychology and neuropsychology. In P. S. Appelbaum, L. A. Uyehara, \& M. R. Elin (Eds.), Trauma and memory: Clinical and legal controversies (pp. 93-137). New York, NY: Oxford University Press.

Madison, B. J. C. (2014). Epistemic internalism, justification, and memory. Logos and Episteme, 5(1), 33-62.

Martin, C. B., \& Deutscher, M. (1966). Remembering. Philosophical Review, 75, 161-196.

McCain, K. (2008). The virtues of epistemic conservatism. Synthese, 164(2), 185-200.

McCain, K. (2014). Evidentialism and epistemic justification. London: Routledge.

McGrath, M. (2007). Memory and epistemic conservatism. Synthese, 157(1), 1-24.

McGrath, M. (2013). Phenomenal conservatism and cognitive penetration: The bad basis counterexamples. In C. Tucker (Ed.), Seemings and justification. Oxford: Oxford University Press.

Michaelian, K. (2011a). The epistemology of forgetting. Erkenntnis, 74(3), 399-424.

Michaelian, K. (2011b). Generative memory. Philosophical Psychology, 24(3), 323-342.

Michaelian, K. (2011c). Is memory a natural kind? Memory Studies, 4(2), 170-189.

Mitchell, K., \& Johnson, M. (2000). Source monitoring: Attributing mental experiences. In E. Tulving \& F. Craik (Eds.), The Oxford handbook of memory. Oxford: Oxford University Press.

Moon, A. (2012a). Knowing without evidence. Mind, 121(482), 309-331.

Moon, A. (2012b). Three forms of internalism and the new evil demon problem. Episteme, 9(4), 345-360.

Pappas, G. S. (1980). Lost justification. Midwest Studies in Philosophy, 5(1), 127-134.

Piazza, T. (2009). Evidentialism and the problem of stored beliefs. Philosophical Studies, 145(2), 311-324.

Poston, T. (2014). Reason and explanation: A defense of explanatory coherentism. New York: Palgrave Macmillan.

Poston, T. (2016). Acquaintance and skepticism about the past. In B. Coppenger, \& M. Bergmann (Eds.), Intellectual assurance: Essays on traditional epistemic internalism. Oxford: Oxford University Press.

Roediger, H., \& McDermott, K. (1995). Creating false memories: Remembering words not presented in lists. Journal of Experimental Psychology: Learning, Memory, and Cognition, 21(4), 803-814. 
Russell, B. (1921/1995). The analysis of mind. London: Routledge.

Schacter, D. L. (2002). The seven sins of memory: How the mind forgets and remembers. Boston: Mariner Books.

Senor, T. D. (1993). Internalistic foundationalism and the justification of memory belief. Synthese, 94(3), 453-476.

Senor, T. D. (2009). Epistemological problems of memory. In E. N. Zalta (Ed.), The Stanford encyclopedia of philosophy. http://plato.stanford.edu/entries/memoryepisprob/.

Tulving, E. (1982). Synergistic ecphory in recall and recognition. Canadian Journal of Psychology/Revue canadienne de psychologie, 36(2), 130-147.

Wagenaar, W. A. (1986). My memory: A study of autobiographical memory over six years. Cognitive Psychology, 18(2), 225-252.

Williamson, T. (2007). On being justified in one's head. In M. Timmons, J. Greco, \& A. Mele (Eds.), Rationality and the good: Critical essays on the ethics and epistemology of Robert Audi. New York: Oxford University Press. 